\title{
A BRIEF ANALYSIS OF MORPHOLOGY AND TERMINOLOGY FOR THE GENUS ABLABESMYIA (TANYPODINAE)
}

\author{
Analía C. Paggi ${ }^{1}$, Augusto Siri ${ }^{1}$ and Caroline Silva Neubern de Oliveira ${ }^{2}$ \\ ${ }^{1}$ Instituto de Limnología “Dr. R.A. Ringuelet” (CONICET, UNLP) C.C. 712, 1900 La Plata, Buenos \\ Aires, Argentina.E-mail: anpaggi@ilpla.edu.ar and augusto@ilpla.edu.ar \\ ${ }^{2}$ Departamento de Zoologia, Universidade Federal do Paraná. Caixa Postal. 19020, Curitiba, Paraná, \\ Brasil. E-mail: cneubern@yahoo.com.br
}

The genus Ablabesmyia is well represented in both the north and south Americas, though the latter region is inadequately studied. A few months ago, the authors of this note made contact to exchange type material and literature on the known species of Ablabesmyia from South America. Almost immediately, we faced the problem that we were referring to the same structures by different names, so we decided to sort and organize the different terminologies used along with the most important bibliography of this genus. Furthermore, we wanted to share the misunderstandings we faced with others who want to study Ablabesmyia so they can learn from our mistakes.

\section{Megaseta of the adult male gonostylus}

When describing the male hypopygium of Ablabesmyia, Johannsen (1946: 271) wrote the following: "styles of the hypopygium about as those of a typical monilis except that the articulated pre-apical stylet is straight and acute at apex”. Roback some years later (1959: 116) separated the main subgenera, Ablabesmyia s. str. and Karelia, by the characteristic "preapical stylet pointed (P) or expanded (E)”, however, the same author used different names for the same structure later in the same paper: "preapical spine of the distyle" and "preapical spur of the distyle has retained the simple apex" (p. 117). Roback (1971: 356, 357 and 365) employed the name "preapical spur”, and in 1982 (p. 106) "spur of dististyle”. In 1983, the same author used "gonostylus spur expanded or sharp” (Roback 1983: 237, table 1).

Later, Roback (1985) introduced the term "megaseta", in his subgeneric adult diagnosis of the subgenera Karelia (p. 169) and Ablabesmyia (p. 178), probably adopting the nomenclature of Sæther \& Sublette (1983) for the homologous structure in Orthocladiinae. Unfortunately, Murray \& Fittkau (1989), in their Tanypodinae diagnosis for the Holarctic genera, erroneously used the term "megaseta" to refer to the apex of the gonostylus: "gonostylus simple...distally with megaseta, mostly without but occasionally with simple or apically expanded subterminal seta (Ablabesmyia)..." (p. 38); followed by "gonostylus as long as or slightly longer than gonocoxite, slender and tapering; megaseta cochleariform with distally expanded or pointed subterminal seta” (p.42). This misunderstanding confused us and generated doubts on which structure actually is the megaseta.

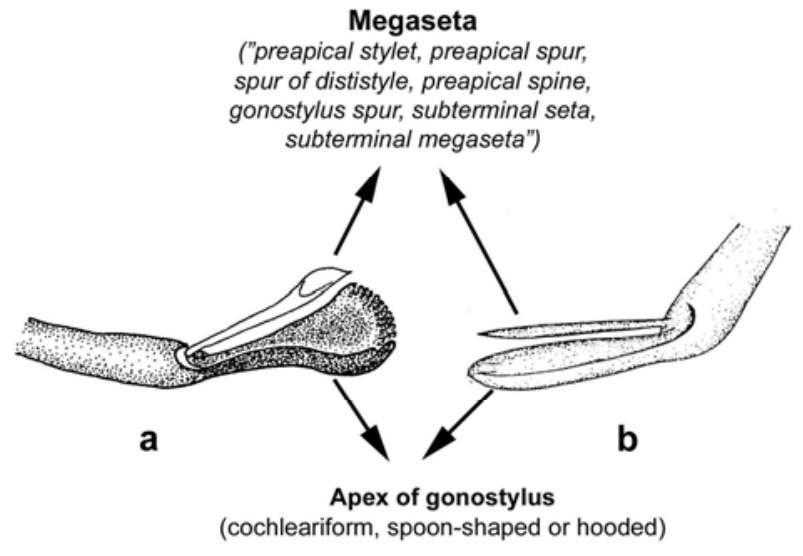

Figure 1. Distal portion of gonostylus. a) extracted from Paggi \& Añón Suarez 2000. b) extracted from Paggi 1987 
In order to clarify and unify the use of terms describing the subterminal seta on the gonostylus of Tanypodinae, we suggest that the name “megaseta” (Roback 1985) should be used. The megaseta lies parallel to the "hooded or cochleariform" apex of gonostylus (Fig. 1). In descriptions of Ablabesmyia hypopygia, it is very important to consider the shape of the megaseta (expanded or sharpened) to differentiate the subgenera and to avoid the wrong interpretation. Furthermore, it is very important to place the structures in their correct position during slide mounting, keeping the apex of the gonostylus and megaseta a little separated from another. The gonostylus should preferably be mounted in lateral view to avoid possible misinterpretations (Fig. 1).

\section{The Aedegal complex}

With regard to the aedeagal complex we also recorded different morphology terminology for the same structures. Roback (1959, 1971) described this complex as being formed of four pairs of structures (aedeagal blades, dorsal lobes, lateral filaments and lateral lobes). Later, Sæther (1980) named these structures volsellas (superior, median and inferior volsellas), but he did not mention the "lateral lobes" described by Roback.
It is possible that they were hidden by the other structures or absent in the examined specimens. Roback (1983) did not agree with Sæther (1980) on the homology of the lobes with the volsellas of the other subfamilies. He introduced the term basidorsal lobe of the gonocoxite and suggested that it might be the true inferior volsella of the other subfamilies. We therefore think it is appropriate to describe the aedegal complex, to accurately name the different structures, and choose one set of terminology to avoid confusion. This has been attempted in Fig. 2.

\section{Maxillary palps in adults and larvae}

Older works on chironomids, describe four palpomeres in the maxillary palp of the adult male. Recent papers describe the palps to consist of 5 segments, following the works by Sæther (1971, 1980). The new interpretation acknowledges the first palpomere as a small, basal, weakly sclerotized segment that is deprived of setae. This means that what was previously considered to be the third palpomere, now is the fourth, and that the fourth palpomere (not the third) is shorter than the third (not the second as described by Fittkau 1962: 416 and Roback 1971: 354).
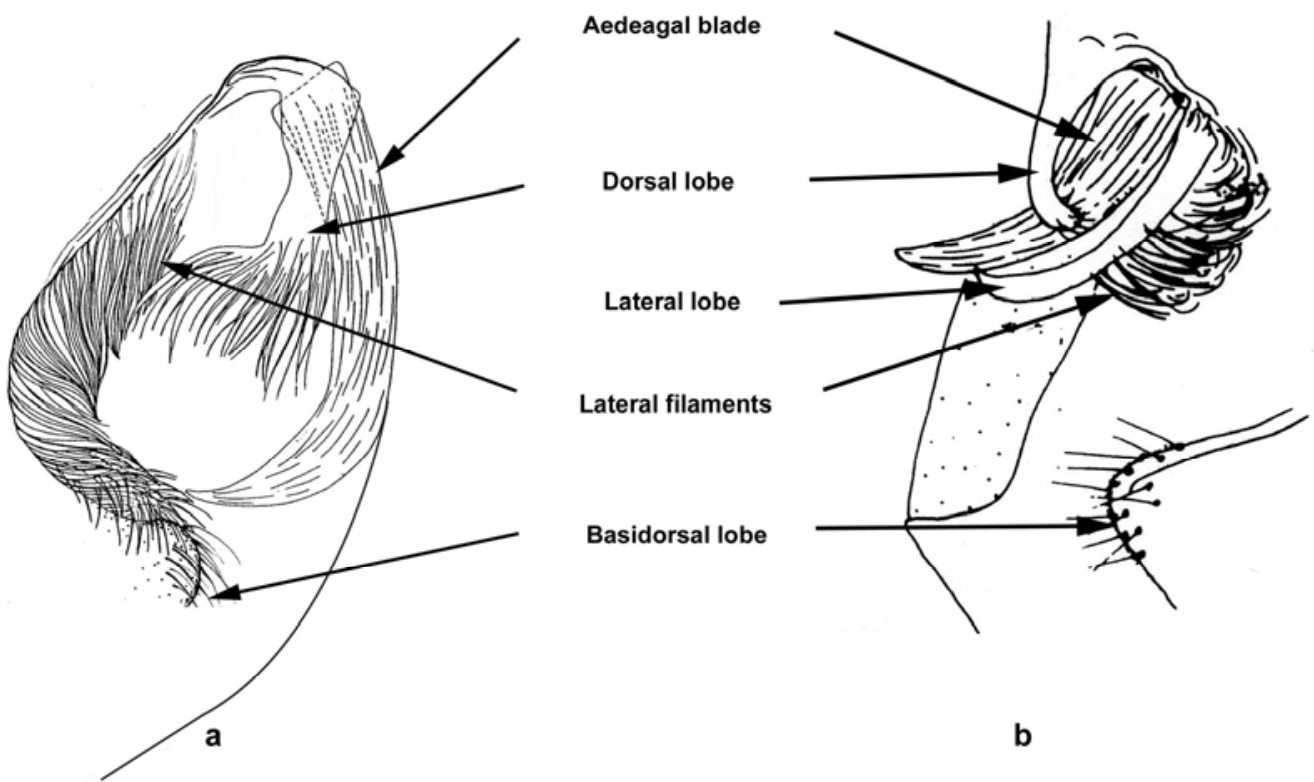

Figure 2. Aedeagal complex. a) Ablabesmyia bianulata, modified from Paggi 1987. b) Ablabesmyia simpsonii, modified from Roback 1985 
Numbering of the larval palpal segments has likewise been done differently by authors and thus caused inconsistency in the calculation of the length ratio between the first and second palpal segments. Roback (1985, fig. 42) started the numbering from the apical palpomere while Epler (2001: 4.20) named the most basal palpomere segment 1 . Since the number of palpomeres in Ablabesmyia larvae increase by the addition of segments basal to the ring organ, we suggest following Roback's (1985) numbering for the future. Thus the palpomere distal to the ring organ should be named P1.

Different use of morphology terminology can easily result in erroneous interpretation of identification keys, both at the subgenus and species level in Ablabesmyia. We hope that the above clarification of names for structures observed in this genus will aid in future nomenclature consistency.

\section{Acknowledgments}

The authors thank Bohdan Bilyj and Torbjørn Ekrem for their comments and suggestions on the manuscript.

\section{References}

Epler, J. H. 2001. Identification Manual for the larval Chironomidae (Diptera) of North and South Carolina. A guide to the taxonomy of the midges of the southeastern United States, including Florida. Special Publication SJ2001SP13. North Carolina Department of Environment and Natural Resources, Raleigh, NC, and St. Johns River Water Management District, Palatka, FL. 526 pp. http:// home.earthlink.net/ johnepler/index.html

Fittkau, E.J. 1962. Die Tanypodinae (Diptera, Chironomidae). Die Tribus Anatopyniini, Macropelopiini und Pentaneurini. - Abh. Larvalsyst. Lnsekten. 6: 1-435.

Johannsen, O.A. 1946. Revision of the North American species of the genus Pentaneura
(Tendipedidae: Chironomidae, Diptera). - J. New York Entomol. Soc. LIV. 4: 267-289.

Murray, D.A. and Fittkau, E. J. 1989. The adult males of Tanypodinae (Diptera: Chironomidae) of the Holarctic Region - Keys and Diagnosis. In: Wiederholm, T. (Ed.), Chironomidae of the Holarctic region - Keys and diagnoses. Part 3. Adult males. - Ent. Scand. Suppl. 34: 37-123.

Roback, S.S. 1959. The subgenus Ablabesmyia of Pentaneura (Diptera, Tendipedidae, Pelopiinae). - Trans. Amer. Ent. Soc. Philad. 85: 113-135.

Roback, S.S. 1971. The adults of the subfamily Tanypodinae (= Pelopiinae) in North America (Diptera: Chironomidae). - Acad. Nat. Sci. Philad. 17: 1-410.

Roback, S.S. 1982. The Tanypodinae (Diptera: Chironomide) of Australia II. - Proc. Acad. Nat. Sci. Philad. 134: 80-112.

Roback, S.S. 1983. Ablabesmyia (Sartaia) metica a new subgenus and species (Diptera: Chironomidae: Tanypodinae). - Proc. Acad. Nat. Sci. Philad. 135: 236-240.

Roback, S.S. 1985. The immature Chironomids of the eastern United States.VI. Pentaneurinigenus Ablabesmyia. - Proc. Acad. Nat. Sci. Philad. 137, 2: 153-212.

Sæther, O.A. 1971. Notes on general morphology and terminology of the Chironomidae (Diptera). - Can. Ent. 103: 1237-1260.

Sæther, O.A. 1980. Glossary of chironomid morphology terminology (Diptera: Chironomidae). - Ent. scand. Suppl. 14: 1-51.

Sæther, O.A. and Sublette, J. E. 1983. A review of the genera Doithrix n. gen., Georthocladius Strenzke, Parachaetocladius Wülker, and Pseudorthocladius Goetghebuer (Diptera: Chironomidae, Orthocladiinae). - Ent. scand. Suppl. 20: 1-100. 